\title{
Screening and identification of amylase producing strains of Bacillus
}

\author{
Kumar Pranay ${ }^{1 *}$, Shree Ram Padmadeo ${ }^{2}$, Vijay Jha ${ }^{3}$, Birendra Prasad ${ }^{3}$ \\ ${ }^{1}$ Department of Biochemistry, Patna University, Patna, India \\ ${ }^{2}$ Department of Botany, Patna University, Patna, India \\ ${ }^{3}$ Microbial and Molecular Genetics Laboratory, Department of Botany, Patna University, Patna, India
}

\begin{tabular}{l}
\hline ARTICLE INFO \\
\hline Article history: \\
Received on: December 06, 2018 \\
Accepted on: January 27, 2019 \\
Available online: July 04, 2019 \\
\hline
\end{tabular}

Key words:

Amylase, fermentation medium,

$16 \mathrm{~S}$ rDNA sequence, Bacillus sp

\begin{abstract}
An attempt was made to isolate and screen efficient amylolytic strains of Bacillus sp. Initial screening based on the starch hydrolysis ratio resulted in the selection of 72 amylolytic bacterial strains. Among these, 18 strains were selected for further studies. Secondary screening based on amylase production in starch broth medium led to the selection of six amylolytic strains of Bacillus sp. The selected strains were grown in four different fermentation media (FMI-FMIV) in order to screen for three most efficient amylolytic strains for optimization and characterization. FMIV was the best basal medium as it provided required nutrients, which stimulated highest amylase production in bacterial strains within shortest incubation time ( 24 hours). Molecular identification based on 16S rDNA sequence revealed that three most efficient strains [BCM36 (KR1), BCM33 (KR2), and BCM25 (KR3)] belonged to Bacillus sp.
\end{abstract}

\section{INTRODUCTION}

Amylases are a group of enzymes that hydrolyze $\alpha-1,4$ glycosidic linkages of starch to yield dextrin and different monomeric products. Microbial amylases are of immense value because of characteristics like bulk production and easy genetic manipulation [1]. Amylases obtained from bacteria are known for greater stability, high productivity and reduced cost of production. The genus Bacillus is a major producer of many extracellular enzymes, including amylases. Bacillus sp. is a preferred choice for industrial production of microbial enzymes due to attributes such as short fermentation cycle, safe-handling, easy manipulation, consistency, efficient enzyme activity under stress conditions, and eco-friendly characteristics [2]. The amylase production from different Bacillus sp. shows a great deal of variation because the production of amylase depends on the composition of medium and other physical parameters. There is a growing need for increasing amylase titer without enhancing the overall cost of production. The present work constitutes a preliminary study of screening

*Corresponding Author

Kumar Pranay, DST-INSPIRE Fellow, Department of Biochemistry,

Patna University, Patna, India.

E-mail: kumar.pranay762@gmail.com the most efficient amylase producing strains of Bacillus sp., their molecular identification, and the selection of most appropriate basal medium for optimization of amylase production.

\section{MATERIALS AND METHODS}

\subsection{Isolation of Microorganisms}

The soil is an extremely rich source of microorganisms. During the present study, the soil samples were collected from various locations of Patna and its surroundings. Previous studies have pointed out that soil rich in garbage waste and agriculture fields are a potent source of different kinds of microorganisms. Sample collection was carried out at sites where garbage from household, vegetable wastes, or industrial wastes decomposes. Samples were collected in every quarter of the year, i.e., January to March, April to June, July to September, and October to December. Samples were taken from a depth of $5 \mathrm{~cm}$. Samples were collected in plastic bags, stored in ice-boxes during transportation, and were refrigerated at $4^{\circ} \mathrm{C}$ until isolation.

For isolation of bacterial strains, the serial dilution method was employed. In this method, the soil sample was weighed $(1 \mathrm{~g})$ and was mixed in $10 \mathrm{ml}$ of normal saline by proper vortexing. Six test tubes were labeled, namely, A, B, C, D, E, and F; each containing 
$9 \mathrm{ml}$ of normal saline. One milliliter of the sample was transferred to tube A making the concentration $10^{-1} \mathrm{ml}$. One milliliter from tube A was transferred to tube $\mathrm{B}$ making the concentration $10^{-2}$ $\mathrm{ml}$ and similar transfers were made to obtain concentrations in the order of $10^{-3}, 10^{-4}, 10^{-5}$, and $10^{-6}$. Each tube was vortexed for even distribution of the sample.

Six nutrient agar plates (NA: agar, $15 \mathrm{~g}$; peptone, $5 \mathrm{~g}$; NaCl, $5 \mathrm{~g}$; beef extract, $3 \mathrm{~g}$; and distilled water, 11) were made and labeled as $1,2,3,4,5$, and 6 . One hundred microliters from each tube containing the sample in decreasing concentrations was transferred aseptically to each NA plate and the sample was evenly spread. The plates were incubated for 24 hours at $37^{\circ} \mathrm{C}$. After 24 hours, colonies were selected on the basis of cultural characteristics and subculturing was done by streaking.

\subsection{Primary Screening of Amylase Producing Bacterial Strains}

Pure cultures were streaked on starch agar plates. Plates were incubated at $37^{\circ} \mathrm{C}$ for 48 hours. After 48 hours, the plates were flooded with Lugol's iodine, which is an indicator of starch. When iodine comes in contact with a medium containing starch, it turns blue. If starch is hydrolyzed, the medium will have a clear zone next to growth. Excess Lugol's iodine was drained off and plates were observed for clear halo zone around the colony against blueblack background. A clear halo zone around the colony indicates amylase production [3].

\subsection{Secondary Screening of Amylase Producing Bacterial Strains}

Secondary screening was based on quantification of amylase in starch broth (SA: agar, $10 \mathrm{~g}$; $\mathrm{NaCl}, 5 \mathrm{~g}$; beef extract, $3 \mathrm{~g}$; and distilled water, 11 at $7.0 \pm 0.1 \mathrm{pH}$ ). A loopful of bacteria was used to inoculate $50 \mathrm{ml}$ of nutrient broth in Erlenmeyer flasks. The flasks were kept on incubator shaker (Vaiometra) at $150 \mathrm{rpm}$ for 24 hours at $37^{\circ} \mathrm{C}$. After 24 hours of growth, $100 \mu 1(3.25 \times$ $10^{7}$ cells $/ \mathrm{ml}$ ) culture was transferred into starch broth media and flasks were incubated at $37^{\circ} \mathrm{C}$ for 24 hours. Amylase assay was performed by 3, 5-Dinitrosalicylic acid (DNSA) method with certain modifications [4]. The assay mixture contained $500 \mu \mathrm{l}$ of soluble starch $(1 \% \mathrm{w} / \mathrm{v}), 500 \mu \mathrm{l}$ of $0.1 \mathrm{M}$ phosphate buffer, and $100 \mu \mathrm{l}$ of appropriately diluted enzyme solution with $\mathrm{pH}$ adjusted to 7 . The reaction was performed at $50^{\circ} \mathrm{C}$ for 15 minutes. The reaction was stopped by the addition of $1 \mathrm{ml}$ of 3,5-dinitrosalicylic acid reagent. Two milliliters of distilled water was also added. The mixture was boiled for 5 minutes and the solution was rapidly cooled in ice water. Absorbance was read at $540 \mathrm{~nm}$ in Systronics UV-VIS spectrophotometer. One unit of enzyme activity was defined as the amount of enzyme required to catalyze the liberation of reducing sugar equivalent to $1 \mu \mathrm{mol}$ of D-glucose per minute under assay conditions.

\subsection{Tertiary Screening of Amylase Producing Bacterial Strains}

Six amylolytic bacterial strains, namely, BCM10, 25, 28, 31, 33 , and 36 selected from the secondary level of screening were evaluated for amylase yield under submerged fermentation
(SmF) conditions in four different fermentation media (FMI-IV). This level of screening was done to select three most efficient amylolytic bacterial strains. The amylase activity assay was done under SmF conditions. Four fermentation media, namely, FMIIV were designed and amylase production by the strains was measured over a course of time by DNSA method [4]. Nutrient broth was used as an activating medium.

\subsection{Molecular Characterization of the Selected Bacterial Strains}

Identification of the organisms was done on the basis of $16 \mathrm{~S}$ rDNA based molecular technique. 16S rRNA gene sequences are the most widely used tool to study bacterial phylogeny and taxonomy. Traits like presence in almost all bacterial species, highly conserved sequence and corresponding function across species and large enough size (1,500 bps) make it the most common genetic marker used.

DNA was isolated from the bacterial cultures and quality was evaluated on $0.8 \%$ agarose gel. Isolated DNA was amplified with 16S rRNA specific primers (8F \& 1492R) using Veriti ${ }^{\circledR} 99$ well Thermal cycler (model No. 9902). The PCR product was enzymatically purified and further subjected to Sanger sequencing. Bi-directional DNA sequencing reaction of PCR amplicon was carried out with 704F and 907R primers using BDT v3.1 Cycle sequencing kit on ABI 3730xl Genetic Analyzer.

\subsection{Phylogenetic Analysis}

The evolutionary history was inferred using the Neighbor-Joining method [5]. The optimal tree with the sum of branch length = 0.11862311 is shown. The evolutionary distances were computed using the Maximum Composite Likelihood method [6] and are in the units of the number of base substitutions per site. This analysis involved 25 nucleotide sequences. Codon positions included were $1 \mathrm{st}+2 \mathrm{nd}+3 \mathrm{rd}+$ Noncoding. All ambiguous positions were removed for each sequence pair (pairwise deletion option). There were a total of 1,683 positions in the final dataset. Evolutionary analyses were conducted in MEGA X [7].

\section{RESULTS AND DISCUSSION}

\subsection{Selection Based on Starch Hydrolysis Ratio}

The primary screening led to the isolation of 72 strains of amylase producing bacteria. The amylolytic bacteria were characterized on the basis of color, configuration, margin, elevation, and mucus. The isolates exhibited highly heterogeneous culture characteristics which were reflection of the diverse microbial flora of the sample sites. Starch hydrolysis ratio (SHR) of 72 strains was calculated according to the equation:

$$
\mathbf{S H R}=\frac{(\text { Clear Halo zone diameter }(\mathrm{mm}))}{\text { Colony growth diameter }(\mathrm{mm})}
$$

The halo zone formation and SHR led to selection of 18 bacterial strains (BCM10, 25, 28, 31, 33, 36, 38, 39, 41, 45, 48, 49, 55, 56, $61,63,66$, and 69) for secondary screening (Table 1). 


\subsection{Selection Based on Amylase Production in Starch Broth}

In secondary screening of the strains (Table 2), BCM36 showed highest activity $(18.20 \pm 0.17 \mathrm{U} / \mathrm{ml})$ followed by BCM 33 (16.51 $\pm 0.16 \mathrm{U} / \mathrm{ml})$ and BCM $25(15.16 \pm 0.22 \mathrm{U} / \mathrm{ml})$. Lowest activity was found in BCM56 $(9.62 \pm 0.13 \mathrm{U} / \mathrm{ml})$. Based on secondary screening, six amylolytic bacterial strains, namely, BCM10, 25, $28,31,33$, and 36 were selected for further investigations.

\subsection{Selection Based on Amylase Titer in Different Fermentation Media}

Tertiary screening involved quantification of amylase and protein in four different fermentation media. In FMI, the highest amylase production was observed after 96 hours of incubation. BCM36 produced highest production $(54.50 \pm 0.381 \mathrm{U} / \mathrm{ml})$, followed by $\mathrm{BCM} 33(36.83 \pm 0.303 \mathrm{U} / \mathrm{ml})$ and BCM25 (33.53 $\pm 0.424 \mathrm{U} / \mathrm{ml})$. BCM28 showed lowest amylase (18.68 $\pm 0.296 \mathrm{U} / \mathrm{ml})$. Significant decline in amylase production was observed after 120 hours of incubation (Fig. 1A). In FMII, all strains except BCM31 (maximum yield after 48 hours of incubation) showed maximum amylase titer after 72 hours of incubation. BCM36 again showed highest production $(61.07 \pm 0.588 \mathrm{U} / \mathrm{ml})$, followed by BCM33 (48.85 \pm $0.258 \mathrm{U} / \mathrm{ml})$ and BCM25 $(46.55 \pm 0.607 \mathrm{U} / \mathrm{ml})$. Lowest amylase production was reported after 24 hours of incubation by all six strains, except BCM28 and BCM31 (lowest yield after 120 hours of incubation, Fig. 1B). In FMIII, highest amylase production was reported for BCM36 after 72 hours of incubation $(74.56 \pm 1.01 \mathrm{U} /$ $\mathrm{ml})$. BCM33 (58.99 $\pm 0.377 \mathrm{U} / \mathrm{ml})$ and BCM25 (50.65 \pm 0.305 $\mathrm{U} / \mathrm{ml}$ ) also showed highest amylase production after 72 hours of incubation. Lowest enzyme production was found in BCM10 $(20.87 \pm 0.232 \mathrm{U} / \mathrm{ml})$ after 48 hours of incubation (Fig. 1C). In FMIV, all the strains showed the highest enzyme production after 24 hours of incubation. Highest enzyme production was observed for BCM36 $(91.04 \pm 1.76 \mathrm{U} / \mathrm{ml})$, followed by BCM33 $(54.60 \pm 2.01$ $\mathrm{U} / \mathrm{ml})$ and BCM25 $(48.44 \pm 2.04 \mathrm{U} / \mathrm{ml})$. Lowest titer was found in $\mathrm{BCM} 10(28.87 \pm 0.388 \mathrm{U} / \mathrm{ml})$. Amylase production declined after 120 hours of incubation for all the strains (Fig. 1D). ANOVA was done to statistically establish the best medium among FMI-FMIV for further optimization. Statistical analysis revealed that FMIV was the best fermentation media for amylase production amongst FMI-FMIV with $p \leq 0.05$ considered significant.

\subsection{Molecular Identification of the Most Efficient Strains}

Phylogenetic analysis revealed that the BCM 36 and BCM 33 were strains of Bacillus subtilis and Bacillus sp., respectively, while BCM 25 was a strain of Bacillus cereus (Fig. 2 and Table 3).

Soil is a rich source of amylase producing bacteria. Soils rich in starchy contents were collected in sterilized polypropylene bags from different areas of Patna and were stored in a refrigerator at $4^{\circ} \mathrm{C}$. Serial dilution and spread plate methods were used for the preliminary isolation of bacteria and different colonies were selected on the basis of cultural characteristics. Pure cultures were obtained after many rounds of streaking. Pure cultures were stored at $4^{\circ} \mathrm{C}$ and were subcultured every 15 days. The pure isolates were screened for amylase production. The screening led to the isolation of 72 amylase positive isolates of bacteria. The most efficient amylolytic bacterial strains were selected on the basis of SHR $[8,9]$.
Table 1: SHR of the selected amylolytic bacterial strains.

$\begin{array}{lccc}\text { Colony no } & \text { Halo zone }(\mathbf{m m}) & \begin{array}{c}\text { Diameter of the } \\ \text { colony }(\mathbf{m m})\end{array} & \begin{array}{c}\text { Starch hydrolysis } \\ \text { zone (SHR) }\end{array} \\ \text { BCM 10 } & 9 & 1.2 & 7.5 \\ \text { BCM25 } & \mathbf{9} & \mathbf{1 . 1} & \mathbf{8 . 1} \\ \text { BCM 28 } & 11 & 1.5 & 7.3 \\ \text { BCM 31 } & 9.5 & 1.7 & 5.5 \\ \text { BCM 33 } & \mathbf{9 . 5} & \mathbf{1 . 3} & \mathbf{7 . 3} \\ \text { BCM36 } & \mathbf{1 0} & \mathbf{1 . 2} & \mathbf{8 . 3} \\ \text { BCM38 } & 11 & 3.6 & 3.0 \\ \text { BCM39 } & 10 & 3.7 & 2.7 \\ \text { BCM41 } & 12 & 4.1 & 2.9 \\ \text { BCM45 } & 15 & 3.5 & 4.2 \\ \text { BCM48 } & 12 & 3.4 & 3.5 \\ \text { BCM49 } & 13 & 3.1 & 4.1 \\ \text { BCM55 } & 17 & 5.2 & 3.2 \\ \text { BCM56 } & 11 & 4 & 2.7 \\ \text { BCM61 } & 16 & 4.2 & 3.8 \\ \text { BCM63 } & 12 & 4 & 3.0 \\ \text { BCM66 } & 11 & 2.5 & 4.4 \\ \text { BCM69 } & 13 & 3.5 & 3.7\end{array}$

Bold values are of the strains selected for tertiary screening and molecular characterization.

Table 2: Secondary screening for amylase production.

\begin{tabular}{lcc} 
Strain no. & Amylase activity $(\mathbf{U} / \mathbf{m l})$ & Growth at $\mathbf{6 2 0} \mathbf{n m}$ \\
BCM10 & $14.53 \pm 0.10$ & $2.51 \pm 0.06$ \\
BCM25 & $15.16 \pm 0.22$ & $2.52 \pm 0.06$ \\
BCM28 & $13.68 \pm 0.10$ & $2.65 \pm 0.02$ \\
BCM31 & $14.19 \pm 0.05$ & $2.35 \pm 0.02$ \\
BCM33 & $16.51 \pm 0.16$ & $2.35 \pm 0.05$ \\
BCM36 & $18.20 \pm 0.17$ & $2.60 \pm 0.05$ \\
\hline
\end{tabular}

Table 3: Description of selected strains on the basis of BLAST ana lysis.

\begin{tabular}{llll} 
Isolate no. & Identified as & NCBI accession no. & $\begin{array}{l}\text { New } \\
\text { nomenclature }\end{array}$ \\
BCM36 & Bacillus subtilis $s p$. & KX354353 & KR1 \\
BCM33 & Bacillus sp. & KX354354 & KR2 \\
BCM25 & Bacillus cereus & KX354355 & KR3 \\
\hline
\end{tabular}

The primary screening led to the isolation of 18 bacterial isolates on the basis of SHR and it has been observed that the size of the halo zone is generally proportional to amylase production [10-14]. Eighteen bacterial isolates were selected for the secondary level of screening. In secondary screening of the strains, BCM36 showed highest activity $(18.20 \pm 0.17 \mathrm{U} / \mathrm{ml})$, followed by BCM $33(16.51$ $\pm 0.16 \mathrm{U} / \mathrm{ml})$ and BCM $25(15.16 \pm 0.22 \mathrm{U} / \mathrm{ml})$. Lowest activity was found in BCM56 $(9.62 \pm 0.13 \mathrm{U} / \mathrm{ml})$. Based on secondary screening, six amylolytic bacterial strains, namely, BCM10, $25,28,31,33$, and 36 were selected for further investigations. Fermentation conditions are known to influence the production of amylase greatly. A tertiary level of screening was performed to 

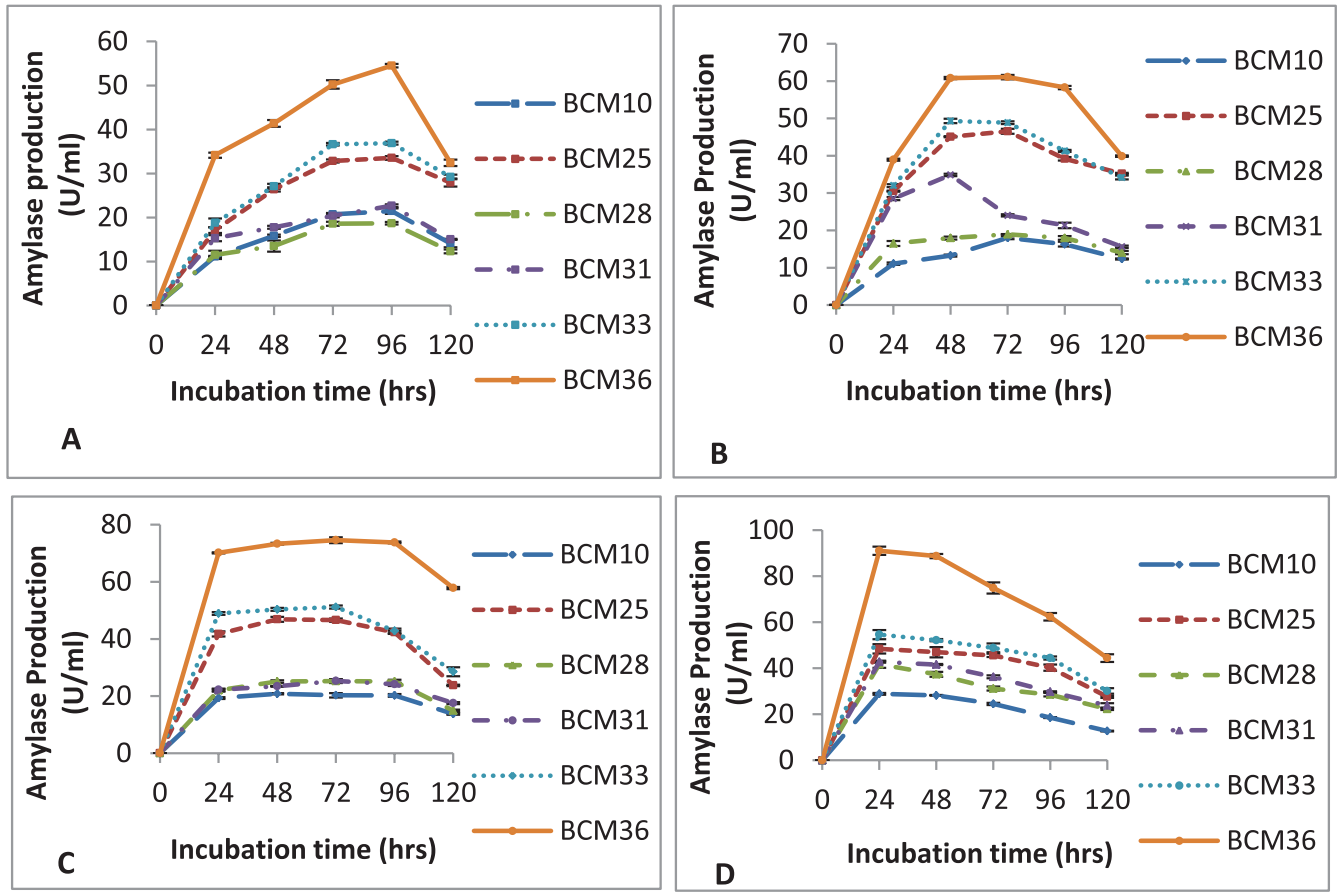

Figure 1: Amylase production in different fermentation media; FMI (A), FMII (B), FMIII (C), and FM IV (D). Erlenmeyer flasks were incubated at $37^{\circ} \mathrm{C}$ up to 120 hours. Amylase production was assayed after every 24 hours. The graph depicts results of triplicate experiments (Mean \pm SE). ANOVA was performed with $p$-value $\leq$ 0.05 considered significant.

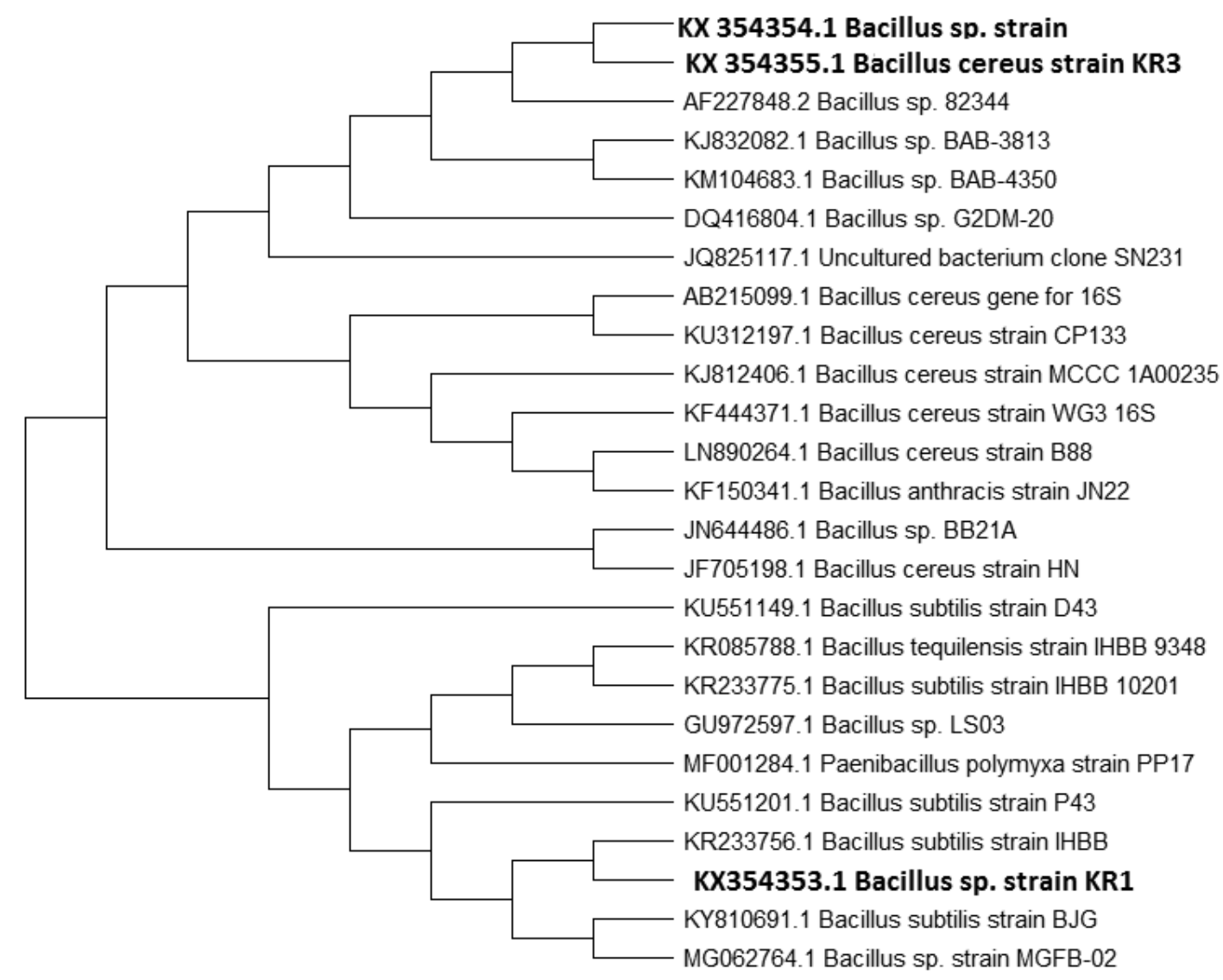

Figure 2: Phylogenetic tree of strains KR1, KR2, and KR3 based on the neighbor-joining method. 
select the most efficient basal media for optimization of amylase production. This selection involved production of amylase under SmF conditions in four different fermentation medium, namely, FMI-FMIV. In terms of composition, FMI was the simplest, while FMIV was a highly enriched medium consisting of salts like $\mathrm{MgSO}_{4}, \mathrm{NaCl},\left(\mathrm{NH}_{4}\right)_{2} \mathrm{SO}_{4}$, and $\mathrm{CaCl}_{2} \cdot 2 \mathrm{H}_{2} \mathrm{O}$. The fermentation studies revealed that highest amylase production was achieved after 96 hours of incubation in FMI, while in FMIV, maximum yield was achieved after 24 hours of incubation. In FMII, all the strains showed highest amylase production after 48 hours of incubation. FMIII also showed highest amylase production after 24 hours of incubation; however, the amount of amylase produced was considerably less in comparison to that of FMIV for each strain. Previous studies have reported efficient amylase production in enriched media from Bacillus subtilis LKS87 [15], Bacllius subtilis KIBGE HAS [16], Bacillus amyloliquefaciens P-001 [17], Bacillus amyloliquefaciens [3], Bacillus sp. [18], Bacillus methylotrophicus strain PII-2 [19], Bacillus sp. TM1 [20], Bacillus Sp. YX-1 [21], Bacillus cereus [22], extreme thermophilic Geobacillus thermoleovorans [23], Bacillus sp. strain TSCVKK [24], Salimicrobium halophilum strain LY20 [25], thermophilic Alicyclobacillus acidocaldarius [26], Bacillus licheniformis [27], Bacillus subtilis KCC103 [28], alkaliphlic Bacillus sp. TS-23 [29], Bacillus licheniformis SKB4 [30], and Bacillus sp. PN5 [31]. In a study conducted on similar lines by Sahoo et al. [32], a Bacillus cereus (sm-sr14), isolated from hot-spring water of Bakreshwar, India, was grown in different mineral salt media for amylase production. In this study, it was observed that growth and amylase production was highest in MS5 media (a mineral salt media). In the present study, it was observed that the maximum amylase production was obtained after 96 hours of incubation in FMI and 24 hours in FMIV. Reduction in enzyme production was reported afterward because of the successive depletion of essential nutrients in the culture medium.

Based on the above mentioned results, it was concluded that FMIV was the best medium for amylase production. Thus, FMIV was selected for optimization. In addition, primary, secondary and tertiary level of screening revealed that BCM25, BCM 33 , and BCM 36 were the most efficient strains of amylolytic bacteria; hence, they were selected for further studies. Based on morphological, biochemical (not shown), and molecular analysis (16S rDNA sequences), it was ascertained that BCM 25 (KR3), BCM 33 (KR2), and BCM 36 (KR3) were strains of Bacillus cereus, Bacillus sp., and Bacillus subtilis, respectively. 16S rDNA sequences are routinely used to establish the molecular credentials of amylase producing bacteria [33,34].

\section{CONCLUSION}

Soil harbors a rich consortium of microbes, and during the present study, it was established that the Patna and its surrounding areas have a rich sink of amylolytic bacteria. A simple and smooth way of selecting the most potent amylase producers was also established during the course of the investigation. Exhaustive screening led to isolation and molecular identification of Bacillus strains, which are industrially most harnessed microbes for amylase production. Further studies like the optimization of amylase production conditions and characterization of amylases under study will establish their industrial potency.

\section{ACKNOWLEDGMENTS}

The work was financially supported by the Department of Science \& Technology (DST), Government of India under DST-INSPIRE fellowship. The infrastructure for the experiments was provided by the Department of Biochemistry, Patna University.

\section{REFERENCES}

1. Souza PM, Magalhaes PO. Applications of microbial $\alpha$-amylase in industry-a review. Brazil J Microbiol 2010;41:850-61.

2. John RJD, Elangovan N. Molecular identification of amylase producing Bacillus subtilis and detection of optimal conditions. J Pharm Res 2013;6:426-30.

3. Abd-Elhahlem BT, El-Saway M, Gamal RF, Abou-Taleb KA. Production of amylases from Bacillus amyloliquefaciens under submerged fermentation using some agro-industrial by-products. Ann Agr Sci 2015;60(2):193-202.

4. Miller GL. Use of dintirosalicyclic acid reagent for determination of reducing sugar. Analyt Chem 1953;31:426-8.

5. Saitou N, Nei M. The neighbor-joining method: a new method for reconstructing phylogenetic trees. Mol Biol Evol 1987;4:406-25.

6. Tamura K, Nei M, Kumar S. Prospects for inferring very large phylogenies by using the neighbor-joining method. Proc Natl Acad Sci (USA) 2004;101:11030-5.

7. Kumar S, Stecher G, Li M, Knyaz C, Tamura K. MEGA X: Molecular Evolutionary Genetics Analysis across computing platforms. Mol Biol Evol 2018;35:1547-9.

8. Thippeswamy S, Girigowda K, Mulimani VH. Isolation and identification of $\alpha$-amylase producing Bacillus sp. from dhal industry waste. Indian J Biochem Biophys 2006;43:295-8

9. Bahadure RB, Agnihotri US, Akarte SR. Assay of population density of amylase producing bacteria from different soil samples contaminated with flowing effluents. Int J Parasitol 2010;2:09-13.

10. Alam KJ, Ruchika P. A study on partial purification and characterization of extracellular amylases from Bacillus subtilis. Adv Appl Sci Res 2011;2:509-19.

11. Mohammed MA, Shivayogeeshwar N, Gurumurthy DM, Rajeshwara AN. Identification, characterization of Novel Halophilic Bacillus cereus Ms6: a source of Extracellular $\alpha$-amylase. Adv Environ Biol 2011;5:992-9.

12. Ghasemi Y, Rasoul-Amini S, Ebrahiminezhad A, Zarrini G, Kazemi A, Mousavi-Khorshidi S, et al. Halotolerant amylase production by a novel bacterial strain, Rheinheimera aquimaris. Res J Microbiol 2010;5:144-9.

13. Mishra S, Behera N. Amylase activity of starch degrading bacteria is isolated from soil receiving kitchen wastes. Afr J Biotechnol 2008;7:3326-31.

14. Das K, Doley R, Mukherjee AK. Purification and biochemical characterization of a thermostable, alkaliphilic extracellular $\alpha$-amylase from Bacillus subtilis DM-03 isolated from the fermented food of India. J Appl Biotechnol Biochem 2004;40:291-8.

15. Park JT, Suwanto A, Tan I, Nuryanto T, Lukman R, Wang K, et al. Molecular cloning and characterization of a thermostable $\alpha$-amylase exhibiting an unusually high activity. Food Sci Biotechnol 2014;23:125-32.

16. Bano S, Qader SAU, Aman A, Syed MN, Azhar A. Purification and characterization of novel $\alpha$-amylase from Bacillus subtilis KIBGE HAS. AAPS PharmSci Tech 2011;12:255-61.

17. Deb P, Talukdar SA, Mohsina K, Sarker PK, Sayem SMA. Production and partial characterization of extracellular amylase enzyme from Bacillus amyloliquefaciens P-001. SpringerPlus 2013;2:1-12. 
18. Khusro A, Barathikannan K, Aarti C, Agastian P. Optimization of thermo-alkali stable amylase production and biomass yield from Bacillus sp. under submerged cultivation. Fermentation 2017;3:1-19.

19. Xie F, Quan S, Liu D, Ma H, Li F, Zhou F, Chen G. Purification and characterization of a novel $\alpha$-amylase from a newly isolated Bacillus methylotrophicus strain PII-2. Process Biochem 2014;49:47-53.

20. Sajedi RH, Manesh HN, Khajeh K, Ranjbar B, Ghalemi N, Manesh MN. Purification, characterization and structural investigation of a new moderately thermophilic and partially calcium independent extracellular $\alpha$-amylase from Bacillus sp.TM1. Appl Biochem Biotechnol 2004;119:41-50.

21. Liu XD, Xu Y. A novel raw starch digesting $\alpha$-amylase from a newly isolated Bacillus sp. YX-1: purification and characterization. Biores Technol 2008;99:4315-20.

22. Kuddus M, Ahmad IZ. Cold-active extracellular $\alpha$-amylase production from novel bacteria Microbacterium foliorum GA2 and Bacillus cereus GA6 isolated from Gangotri glacier, Western Himalaya. J Genet Eng Biotechnol 2012;10:151-9.

23. Nisha M, Satyanarayana T. Characterization and multiple applications of a highly thermostable and $\mathrm{Ca}^{+2}$-independent amylopullanase of the extreme thermophilic Geobacillus thermoleovorans. Appl Biochem Biotechnol 2014;174:2594-615.

24. Kiran KK, Chandra TS. Production of surfactant and detergentstable, halophilic, and alkalitolerant $\alpha$-amylase by a moderately halophilic Bacillus sp. Strain TSCVKK. Appl Microbiol Biotechnol 2008;77:1023-31.

25. Li Xiu, Yu Y. Purification and characterization of novel-organicsolvent-tolerant $\beta$-amylase and serine protease from a newly isolated Salimicorbium halophilum strain LY20. FEMS Microbiol Lett 2012;329:204-11.

26. Kumar GS, Chandra MS, Mallaiah KV, Sreenivasulu P, Choi YL. Purification and characterization of highly thermostable $\alpha$-amylase from thermophilic Alicyclobacillus acidocaldarius. Biotechnol Bioproc Eng 2010;15:435-40.

27. Rao MD, Ratnam BVV, Ramesh DV, Ayanna C. Rapid method for the affinity purification of thermostable $\alpha$-amylase from Bacillus licheniformis. World J Microbiol Biotechnol 2005;21:371-5.
28. Nagarajan DR, Rajagopalan G, Krishnan C. Purification and characterization of a maltooligosaccharide-forming alpha-amylase from a new Bacillus subtilis KCC103. Appl Microbiol Biotechnol 2006;73:591-7.

29. Chi MC, Chen YH, Wu TJ, Lo HF, Lin LL. Engineering of a truncated alpha-amylase of Bacillus sp.strainTS-23 for the simultaneous improvement of thermal and oxidative stabilities. J Biosci Bioeng 2010;109:531-8.

30. Samanta S, Das A, Halder SK, Jana A, Kar S, Mahopatra PKD, et al Thermodynamic and kinetic characteristics of $\alpha$-amylase from Bacillus licheniformis SKB4. Acta Biol Szegediensis 2014;58(2):147-56.

31. Saxena RK, Dutt K, Agarwal L, Nayyar P. A highly thermostable and alkaline amylase from a Bacillus sp. PN5. Biores Technol 2007;98:260-5.

32. Sahoo S, Roy S, Maiti S. Production and partial purification of hyperthermostable alkaline amylase in a newly isolated Bacillus cereus (sm-sr14) from Hot Spring water. Res J Microbiol 2017;12:187-201.

33. Dash BK, Rahman MM, Sarker PK. Molecular identification of a newly isolated Bacillus subtilis BI19 and optimization of production conditions for enhanced production of extracellular amylase. BioMed Res Int 2015;Article ID 859805:9.

34. Sen SK, Raut S, Satpathy S, Rout PR, Bandyopadhyay B, Mohapatra PK. Characterizing novel thermophilic amylase producing bacteria from Taptapani hot spring, Odisha, India. Jundishpur J Microbiol 2014;7(12):e11800.

How to cite this article:

Pranay K, Padmadeo SR, Jha V, Prasad B. Screening and identification of amylase producing strains of Bacillus. J Appl Biol Biotech 2019;7(04):57-62. DOI: 10.7324/ JABB.2019.70409 